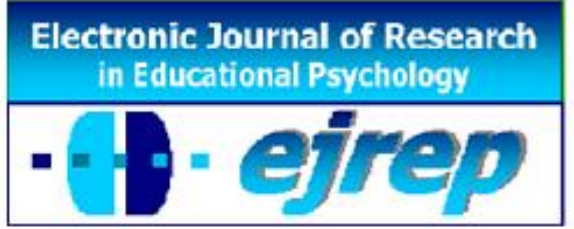

\title{
Feelings and performance in the first year at university: Learning-related emotions as predictors of achievement outcomes in mathematics and statistics
}

\section{Alexandra C. Niculescu ${ }^{1}$, Dirk Tempelaar ${ }^{2}$, Jimmie Leppink ${ }^{3}$, Amber Dailey-Hebert ${ }^{4}$, Mien Segers ${ }^{1}$ \&'Wim Gijselaers ${ }^{1}$}

${ }^{1}$ Educational Research and Development Department, Maastricht University School of Business and Economics, Netherlands

${ }^{2}$ Quantitative Economics Department, Maastricht University

School of Business and Economics, Netherlands

${ }^{3}$ Educational Development and Research Department, Maastricht University Faculty of Health, Medicine and Life Sciences, Netherlands

${ }^{4}$ School of Graduate and Professional Studies, Park University, United States

Netherlands

Correspondence: Alexandra Corina Niculescu, PO Box 616, 6200 MD Maastricht, Netherlands. E-mail: a.niculescu@maastrichtuniversty.nl

(c) Education \& Psychology I+D+i and Ilustre Colegio Oficial de la Psicología de Andalucía Oriental (Spain) 


\begin{abstract}
Introduction. This study examined the predictive value of four learning-related emotions Enjoyment, Anxiety, Boredom and Hopelessness for achievement outcomes in the first year of study at university.

Method. We used a large sample $(N=2337)$ of first year university students enrolled over three consecutive academic years in a mathematics and statistics course, from an undergraduate Economics and an International Business degree programs.

Results. We first showed significant differences in the emotional experiences between the students who attended, and those who were absent from the final exam. Second, the present study found emotions to have a strong predictive value for student exam scores, particularly for learning hopelessness and a prior mathematics background. This relationship was consistent over three consecutive academic years.
\end{abstract}

Discussion and Conclusion. Recommendations for improving educational practice have been formulated and are shared in this article.

Keywords: Achievement outcomes; Learning-related emotions; First year of university; Mathematics and statistics. 


\section{Sentimientos y rendimiento en el primer curso universitario: las emociones como predictores de resultados académicos en las matemáticas y la estadística}

\section{Resumen}

Introducción. Este estudio examinó el valor predictivo de cuatro emociones relacionadas con el aprendizaje -disfrute, ansiedad, aburrimiento y desesperación- en los resultados académicos de alumnos en primer año de carrera universitaria.

Método. Usamos una muestra amplia $(N=2337)$ de estudiantes de primero de carrera matriculados durante tres años académicos consecutivos en un curso de matemáticas y estadística de programas de grado en Economía y Comercio International.

Resultados. Primero encontramos diferencias significativas en las experiencias emocionales entre los estudiantes que realizaron el examen final y los que no. Segundo, se encontró que las emociones tienen un elevado poder predictivo en las notas obtenidas en el examen por los alumnos, especialmente desesperación relacionada con el aprendizaje y conocimiento previo sobre matemáticas. Esta relación se mantuvo a lo largo de tres cursos académicos consecutivos.

Discusión y conclusión. Se presentan recomendaciones para mejorar la práctica educativa.

Palabras clave: Resultados de logro; Emociones relacionadas con el Aprendizaje; Primer año de Universidad; Matemáticas y estadística. 


\section{Introduction}

The first year of university is a crucial area to investigate, notoriously recognized as a period of transition in which a significant majority of students experience adjustment difficulties. The struggle of this transition period involves novel situations that challenge students to make academic, social, and emotional adjustments in order to adapt to their new educational environment (Baker \& Siryk, 1984; Daniels et al., 2014; Pascarella \& Terenzini, 1991). Tinto's (1987) research provides a classic demonstration of how students' adaptation to a new learning environment is the key to understand how they perform academically. Likewise, other studies have shown that poor adjustment was linked to low achievement scores (Credé \& Niehorster, 2012) and even withdrawal at the course level (Ruthig et al., 2008). For instance, Credé and Niehorster's (2012) meta-analysis found correlations between college GPA and different adjustment constructs - ranging from $r=.09$ (for social adjustment) to $r=.32$ (for academic adjustment).

In relation to adaptation, classical approaches have also identified that student variables - such as personality, cognitive factors or demographics - are indeed able to predict achievement outcomes in college (Arias Ortiz \& Dehon, 2013; Credé \& Niehorster, 2011, 2012; Noftle \& Robins, 2007; Poropat, 2009). For example, a meta-analysis of the Five Factor Model of Personality (Poropat, 2009) finds Conscientiousness consistently associated with college GPA (a population correlation of $r=.24$ ). Despite reaching acceptable predictive values for achievement outcomes in these approaches, which focused on student variables, substantial variance has been left unaccounted for (Pascarella \& Terenzini, 2005).

More recently, contemporary research has introduced the importance of academic emotions on achievement outcomes (Pekrun \& Linnenbrink-Garcia, 2014). Pekrun's work (2000, 2006) has emerged as one of the first frameworks to acknowledge the centrality of emotions in achievement settings. This line of research demonstrates relatively stronger relationships with achievement outcomes, as shown in substantial correlations of discrete emotions and individual performance in the $.30-.50$ range (Pekrun et al., 2011).

Over the past twenty years, serious theoretical advances have been made on understanding the role of academic emotions in achievement situations (Goetz et al., 2006; Pekrun, 1992; Stöber \& Pekrun, 2004; Zeidner, 1998). However, a lack of empirical research exists on the role these emotions have in explaining achievement outcomes (Linnenbrink, 2006; Elliot 
\& Pekrun, 2007) and in explaining ecologically valid situations (such as when students enter university). Therefore, to better predict achievement outcomes in the first year of college, more research is needed on the role of academic emotions in these settings. To fill in this gap, our study aims to investigate the predictive value of achievement emotions on course outcomes among first year university students.

In the following section, we will first introduce academic emotions and then describe the particular types of academic emotions experienced within the different settings of a course. Next, we will summarize the empirical evidence linking academic emotions with achievement outcomes in the first year of university - more specifically, in mathematics and statistics courses. We conclude this section with the specific aim and the hypotheses of our study.

\section{Conceptual framework}

To get a better understanding and prediction of achievement outcomes, contemporary research on self-regulated, motivational and emotional learning has emphasized aspects of students' psychological well-being and the resulting influence on academic achievements (Pekrun et al., 2002; Tempelaar et al., 2012). To date, two recent review studies (Robbins et al., 2004; Richardson et al., 2012) conclude that individual characteristics, such as selfefficacy, effort regulation, and achievement motivation are highly correlated with learning outcomes. In particular, Pekrun's work (2000) expands on this perspective and describes academic emotions as subjective experiences, which arise as a reaction to the course setting. Academic emotions are defined in this context as "emotions that are directly linked to achievement activities and outcomes" (Pekrun et al., 2011, p. 37). Therefore, research on academic emotions prompts a re-appraisal of the classical models on self-regulated and motivational learning, to address the student experience within a specific course (Pekrun et al., 2002). Of particular relevance is the role of academic emotions in abstract or difficult subjects, such as Mathematics and Statistics. In such courses, even for students with high cognitive abilities, learning is impeded by negative attitudes and beliefs students hold towards such courses (Gal \& Ginsburg, 1994; Garfield \& Ben-Zvi, 2007). Not surprisingly, research shows that students experience elevated levels of unpleasant emotions when enrolled in courses on Mathematics or Statistics (Dettmers et al., 2011). Furthermore, Dettmers' et. al. study found that elevated 
levels of negative emotions influence students' amount of effort and disengagement from study, to predict negative achievement in mathematics.

\section{Academic emotions and the Control-Value Theory of Achievement Emotions}

The Control Value of Achievement Emotions (CVTAE; Pekrun, 2006) builds upon classical theories of emotions, such as expectancy-value (Pekrun, 1992; Turner \& Schallert, 2001), transactional approaches (Lazarus \& Folkman, 1984) and attribution theory (Weiner, 1985). It also builds upon contemporary models of emotions and their effects on performance (Fredrickson, 2001; Pekrun et al., 2002; Zeidner, 2007). However, CVTAE goes beyond these approaches by placing the emotional experiences in achievement situations, which helps to distinguish between two types of emotions: activity and outcome-related emotions (Pekrun et al., 2011). For instance, boredom felt while attending lectures is an activity emotion; and anxiety anticipated towards the exam is an outcome-related emotion. Pekrun (2006) follows contemporary theories on process emotions (Scherer, 2005), to describe emotions as "sets of interrelated psychological processes including affective, cognitive, physiological and motivational components" (Pekrun et al., 2011, p. 37). For example, being uneasy, worrying, being aroused, or wishing to quit a course, reflect these different components within an emotion. The CVTAE further depicts emotions as having a valence. In this respect, emotional valence can be either positive (enjoyment) or negative (anxiety, hopelessness, boredom). Beyond this distinction, an important attribute of academic emotions in the CVTAE is the situational context, in which the emotional experiences are contextualized over different achievement situations within a course: being in class, taking exams and studying outside of class. To summarize, academic emotions can be described in terms of: 1) activity or outcome, dependent upon their focus; 2) valence, as either positive or negative emotions, and 3) situational context, depending on the different settings of a course in which emotions are experienced (in class, while learning, or while completing an exam). Finally, CVTAE proposes that academic emotions predict learning related behaviors (such as learning strategies), which in turn influence achievement outcomes.

\section{Learning-related emotions and achievement outcomes}

According to Pekrun et al. (2002), the three most important academic settings to experience emotions in a course include: 1) being in class, 2) taking tests and exams, and 3) study- 
ing outside of class. As a consequence, each setting is used to measure one type of emotion: class-related, test-related and learning-related emotions. Learning-related emotions (LREs) are a particular type of achievement emotions, usually experienced in learning situations outside classroom instruction, such as studying or doing homework (Goetz et al., 2012; Pekrun et al., 2002; Pekrun et al., 2011). While other emotional settings, such as taking texts/exams, have been extensively studied, few studies have investigated situations that occur outside the class (Linnenbrink, 2006; Schutz \& Pekrun, 2006; Putwain, Sander et al., 2013; Trautwein et al., 2009). An exception is research on test emotions, (test anxiety in particular), where accepted interventions are helpful in training students to deal with their negative emotional states before or during the exam (Ergene, 2003). While this approach helps students manage negative emotions and clearly benefits the learner in the limited setting of an exam, its scope does not capture the full experience of the learning process for the duration of a full-length course. In order to get more insight into students' emotional experiences outside of the exam situation, investigating the learning situation within a course is needed. In this context, LREs are of particular relevance given their substantial relation with achievement outcomes as shown in correlations as high as $r=.41$ (Goetz et al., 2012). In addition, learning in this setting (e.g. while preparing homework) evokes stronger negative emotions when compared, for example, with the emotional experience of learning in the classroom (Verma et al., 2002). To capture more of the students' emotional experiences within the different learning settings encountered in a course, our study links learning-related emotions and achievement outcomes at the course level. To address this issue we excluded test and class-related emotions and focused solely on the emotional experience of studying outside the classroom, either during individual study or when preparing homework.

\section{Empirical evidence linking learning-related emotions and achievement outcomes}

Earlier advances have supported the influence of emotional experiences on academic performance by providing empirical evidence with a main focus on domain differences (Leone \& Richards, 1989; Verma et al., 2002). More recently, the focus was brought on structural relations between different types of academic emotions and achievement outcomes (Dettmers et al., 2011; Goetz et al., 2012; Goetz et al., 2013; Stephanou, 2011). This recent research discusses students' emotional experiences during mathematics homework (Dettmers et al., 2011; Goetz et al., 2012). Generally speaking, the homework assignments are considered "emotionally charged activities" (Dettmers et al., 2011, p. 25), where students seem to 
experience the most unpleasant emotions when compared with other academic situations (Leone \& Richards, 1989). For instance, Dettmers et. al. (2011) focused on the experience of unpleasant emotions during homework and demonstrated how elevated anxiety and boredom levels shape effort and disengagement in study, to predict negative achievement in mathematics. Dettmers et al. study, conducted in a sample of $9^{\text {th }}$ and $10^{\text {th }}$ grade students, found correlation between unpleasant emotions and mathematics achievement in the range of $r=-.14$ to $r=$ -.26. Similar values were displayed by Goetz et al. (2012) in a sample of $11^{\text {th }}$ grade students: the range of correlations between homework emotions and mathematics achievement was between $r=.03$ and $r=.41$. Overall, these studies have shown that LREs are able to predict course achievements in primary (Leone \& Richards, 1989; Verma et al., 2002) and secondary education (Dettmers et al., 2011; Goetz et al., 2012). To our best knowledge, LREs in the first year of university have received little attention (Putwain, Sander, \& Larkin, 2013; Putwain, Larkin, \& Sander, 2013; Tempelaar et al., 2012) despite their potential to predict achievement outcomes. There remains a window in the first year of university in which more empirical evidence could be added on the role of LREs in predicting achievement outcomes (Beard, Clegg, \& Smith, 2007). This is especially relevant now, when the study of students' emotional experiences and coping strategies still forms an almost neglected field (Linnenbrink-Garcia \& Pekrun, 2011).

\section{This study}

Building on Pekrun's framework, we focus on four academic emotions experienced in learning-related situations: the positive emotion Enjoyment and the negative emotions Anxiety, Boredom and Hopelessness. Class-related emotions and test emotions were deemed to be beyond the scope of our study, as learning Enjoyment, Anxiety and Boredom are shown to be particularly salient in academic settings (Goetz et al., 2006).

\section{Aim}

The present study examines the predictive value of four learning emotions - Enjoyment, Anxiety, Boredom and Hopelessness - on two achievement outcomes within a mathematics and statistics course: 1) participation in the final exam and, for those students who attended the exam, 2) explain their performance in the course. 


\section{Hypotheses}

Previously, research has shown that negative LREs have a strong impact on academic performance in mathematics and statistics domains (Dettmers et al., 2011) as well as other subjects (Putwain, Larkin, et al., 2013; Trautwein et al., 2009). Furthermore, in introductory courses, negative emotions are able to predict student withdrawal at the course level (Ruthig et al., 2008). In particular Hopelessness, a "neighboring emotion" of Anxiety, has shown high correlation with achievement outcomes and an ability to longitudinally predict disengagement from study (Pekrun et al., 2002, 2004). In line with these previous findings, we hypothesize the four LREs to have an influence on two achievement outcome in a course: 1) on the participation in final exam and, for those who participated in the exam, 2) on their overall performance in the course. We formulated the following hypotheses:

H1. Students who were absent for the exam show less learning Enjoyment, more learning Anxiety, more Boredom, and more Hopelessness than the students who attended the exam.

H2. The positive emotion enjoyment, has a positive influence on students' performance; the negative emotions, anxiety, boredom and hopelessness, have a negative influence on performance.

\section{Method}

\section{Participants}

The sample consisted of first year university students $(N=2337)$, enrolled in an undergraduate Economics and an International Business degree programs at a Dutch University over three consecutive academic years $2010(N=600), 2011(N=847)$ and $2012(N=890)$. In the academic year 2010, the students were on average 20.0 years (range $17.4-30.7$ ), in 2011 the average age was 21.3 (range 18.2 - 41.7), and in 2012, 19.6 (range 17.0 - 27.4). In all three academic years, most of the students were male $(60.6 \%$ in $2010,64.6 \%$ and $62.2 \%$ in 2011 and 2012, respectively). The participants had a predominantly international background, with a vast majority of German nationality $(55.2 \%$ in $2010,58.5 \%$ in 2011 and $51.7 \%$ in 2012), followed by Dutch (28.5\% in 2010, $24.2 \%$ in 2011, and $27.4 \%$ in 2012) and Belgian (5.2\% in $2010,5.6 \%$ in 2011, and $6.0 \%$ in 2012), while the remaining were mostly European. 
Consequently, most students had a foreign $(66.7 \%$ in $2010,78.8 \%$ in 2011 and $66.9 \%$ in 2012) instead of a Dutch secondary education diploma. Overall, a high proportion of our participants had previously been educated in the field of mathematics (25.4\% had a MathMajor level for the year 2010, 32.4\% for 2011 and $33.1 \%$ for 2012).

\section{Setting}

The program offered by this school has two main characteristics: first, it has a strong international focus which is reflected in a high proportion of students with an international background and, in English being the main language of instruction. Second, the university uses Problem-Based Learning (PBL) as its leading educational approach (Barrows \& Tamblyn, 1980). PBL involves students working in small groups to solve problems under the guidance of a tutor (Wilkerson \& Gijselaers, 1996). While PBL is the dominant mode of instruction, in a limited number of courses, the tutorial groups are supplemented by traditional lectures. The course chosen as a setting in the present study, Quantitative Methods I (QM I) represents a combination of both educational approaches. QM I is a compulsory introduction to mathematics and statistics, in which students from both Economics and International Business tracks enroll. The course is scheduled in the first term of the academic year, and is the first of a series of required courses in our faculty. It has a duration of eight weeks (out of which, seven weeks are scheduled for education and the last week is reserved for exams). In weeks three, five and seven of the course, voluntary math and statistics quizzes are planned which, if performed successful, would add a bonus score to the final course grade. Every week, students are expected to prepare homework assignments which, if solved, grant students some bonus points. This course has a high audience (approximately 1000 students each year) and is notoriously known among new students for two main reasons. First, the material is often regarded as being difficult and unattractive; mathematics concepts are difficult for students who either lack, or only have poor prior knowledge. Second, this is a key course for first years entering our faculty, as failing one of the QM courses directly implies issues of study delay in the first year at this university. These reasons, together with the fact that the design of the course remained unchanged over the years, made QM I a good candidate for testing the hypotheses assumed in our study. 


\section{Design and Procedure}

In week four of the course participants completed an online questionnaire about their LREs regarding the specific subject of the course. The timing was chosen to capture sufficient experience of the learning activities. In the last week of the course students participated in the written exam. For issues of cross validation, these measurements and the timing were kept identical and repeated over three consecutive academic years in 2010, 2011 and 2012. All students included in this study provided informed consent for the use of data collected by means of online questionnaires and in order to link the data with their study results.

\section{Variables and Measures}

Learning-related emotions (LREs) were the independent variables in the present study, measured through the four learning scales, Enjoyment, Anxiety, Boredom and Hopelessness, of the Achievement Emotions Questionnaire (AEQ) developed by Pekrun et al. (2011). Considering that LREs are a specific type of academic emotions which entail several components (cognitive, behavioral, motivational and affective), the AEQ construction takes these components into account for each emotion scale. Items were answered on a 7-point Likert scale $(1=$ 'completely disagree' and $7=$ 'completely agree') and re-phrased to better match the subject investigated in this study. The AEQ is a self-report questionnaire with good psychometric qualities: both the factorial validity and the internal consistency of the learning-related scales of the AEQ have been evidenced in the literature (Pekrun et al., 2011). In our study, the factorial validity was acceptable (see Table 2 ), while the reliability coefficients were very good (see Table 4).

Student participation in the final exam was the first outcome variable, allowing for absence and attendance at the exam. Exam participation was operationalized through having obtained or lacking a grade after the first round of examinations took place.

Student achievement was the second outcome variable, measured through the official QM I grade, which was comprised of three separate parts: MathPerformance, StatsPerformance and BonusPerformance. First, the two performance outcomes MathPerformance and StatsPerformance were assessed in a final written exam which covered a mathematics component and a statistics component, graded separately. Second, the BonusPerformance represented the sum of bonus scored in quizzes and homework. Quizzes, although optional, were available for both mathematics and statistics in an online format. Some further bonus could be achieved by doing weekly homework, containing assignments for mathematics and statistics. 
Additionally, given the strong diversity in nationalities in the current sample, a factor we accounted for was prior education. There are considerable differences in the secondary education systems, which can affect the overall performance in a mathematics and statistics course. For most educational systems, the difference is made at three minimum levels which prepare their graduates for higher education: programs aimed for arts and humanities, programs for social sciences, and programs for sciences. To enroll in an Economics or International Business track at our university, students are required to have been educated at an intermediate level, which is provided in a social sciences program. Although the required levels are assumed to be equivalent across countries, the national curricula differ based on the focus given to mathematical topics. Even within a nation, another source of diversity can be found in the type of mathematical specialization (minor and major) of student's high school education. In social sciences programs it can be expected that all students had, at minimum, a mathematics minor specialization. Last but not least, a gender gap seems to persist in secondary education with respect to higher levels of Anxiety towards Mathematics, more frequently reported by female rather than male students (Hyde et al., 1990). This is intriguing, as no actual relevant differences between the females and males are actually documented with respect to achievement outcomes (Lindberg et al., 2010). Given this evidence, another factor we accounted for was gender. Therefore, as control variables we included gender (Female and Male), prior education in terms of secondary education diploma (International versus Dutch Diploma or $V W O$ ) and level of introductory mathematics education (distinguishing between two tracks, MathMajor and MathMinor) to account for potential differences in students' LREs (Pekrun et al., 2002, 2004) and when predicting achievement that might be due to prior mathematical education rather than emotions (cf. Tempelaar et al., 2012).

\section{Preliminary data analysis}

In order to investigate the factorial validity of the four LREs assessed with the AEQ, we used confirmatory factor analysis (CFA), a latent variable approach. Prior to fitting the measurement models, we checked the assumptions of normality at item level through SPSS 21. Values of skewness and kurtosis were in the expected range of chance fluctuations in that statistic. Mplus version 7 (Muthén \& Muthén, 2012) was used to perform CFA. Because no large departures from normality were detected, we used Maximum Likelihood estimation. Given the relatively large sample size, we report the Chi-square/degrees of freedom ratio instead of the p-value (Byrne, 2011), an index with a recommended value smaller than two (Schermelleh-Engel et al., 2003). In addition, we report the Comparative Fit Index (CFI), the 
Non-Normed Fit Index (NNFI, also known as TLI) and the Root Mean Square Error of Approximation (RMSEA) as indicators of goodness of fit. Hu and Bentler (1999) suggested for CFI/TLI values larger than .90 for a satisfactory fit and for RMSEA values should not exceed .08 and preferably be .06 or lower.

Before proceeding with further analyses, another set of normality checks was run on the adjusted scales (cf. CFA,) which showed no serious departures from normality (i.e., no extreme skewness, multimodality or any extreme cases).

\section{Testing hypotheses}

H1 was investigated by means of MANOVA in which all four LREs were treated as correlated responses and absence at exam as factor. To control for gender effects, prior education, and level of introductory mathematics, we also included these variables in the MANOVAs, and the multiple linear regressions. Finally, we estimated models which included the prediction of each LRE by all demographic variables. Next, we performed a multiple linear regression to investigate the predictive value of the four learning emotions for achievement outcomes in each academic year (H2). All analyses were based on a subset of students for which background characteristics, LREs variables and performance data were all available. This subset comprised 2337 students, $80.09 \%$ of the total of 2918 students enrolled.

\section{Results}

\section{Tests of factorial invariance of the four LREs}

Since our hypotheses proposed to test the same relations over three different time instances of the same course using the same instrument, there is an implicit assumption that the instrument structure is the same at each point of measurement. It is therefore necessary to demonstrate the factorial validity equivalence of the instruments used with each of the three measurement occasions.

For this purpose, we ran three first-order CFA models employed over the three cohorts in all academic years (2010, 2011 and 2012). We started with confirming the theoretical model described in the original AEQ, based on 43 items serving as indicators for the four dimensions of the academic emotions. The results of this analysis are reported as basic model $(A)$ and are presented in Table 1. Some fit problems were found $\left(\chi^{2} / \mathrm{df}>3\right.$, CFI and TLI below 0.90). In all data sets, the factor loadings were significant (all $p<.01$ ). However, the $R^{2}$ was 
below .25 for two items (LJOP1D and LJOP2D) ${ }^{1}$. We also found high correlations (factor $r$ above .80 ) between the Anxiety and Hopelessness factors, as the two are known as "neighboring" emotions and have already been shown as highly correlated (Pekrun et al., 2002, 2004). The correlations between the other factors though, ranged from about .40 (for Boredom and Anxiety, for example) to .60 (Hopelessness with Enjoyment).

Table 1. Basic model (A):

4 factors (Enjoyment, Anxiety, Boredom, Hopelessness) with no cross-loadings

\begin{tabular}{llllll}
\hline Time point & $\chi 2, \mathrm{df}$ & CFI / TLI & RMSEA (95\%CI) & $\begin{array}{l}\text { Items R2 below } \\
0.25\end{array}$ & Factor r above 0.80 \\
\hline 2010 & 3394.162, & $\begin{array}{l}0.865 / \\
0.857\end{array}$ & $0.070(0.068 ; 0.073)$ & LJOP1D, LJOP2D & A-H: 0.898 \\
& 854 & & & \\
2011 & 3661.659, & $0.876 /$ & $0.062(0.060 ; 0.064)$ & LJOP1D, LJOP2D & A-H: 0.911 \\
& 854 & 0.869 & & & \\
2012 & 4029.202, & $0.877 /$ & $0.065(0.063 ; 0.067)$ & LJOP1D, LJOP2D & A-H: 0.890 \\
& 854 & 0.870 & & & \\
\hline
\end{tabular}

Note. $\mathrm{A}=$ Anxiety; $\mathrm{H}=$ Hopelessness.

Furthermore, better fit on the separate data sets (see Table 2) was achieved after adjusting the model in two stages: first, by consecutively removing nine items, out of which six reflected the physiological component of each of the enjoyment, anxiety and hopelessness scales (LJOP1D, LJOP2D, LJOC2A, LJOM3A, LAXP2D, LAXP2D, LAXC3A, LHLP1B, LHLP2D). Then, following the recommended high modification indices, two residual covariance paths (LBOA1D with LBOC3D; LHLC2A with LHLC1D) ${ }^{1}$ were added. Both LBOA1D and LBOC3D items refer to excessive boredom experienced during studying for this course; LHLC2A and LHLC1D) describe resignation concerning the abilities to learn in the course. Table 3 gives the full overview of standardized factor loadings, factor correlations, and residual covariance paths for the adjusted model (B).

\footnotetext{
${ }^{1}$ According to the AEQ item labels 
Table 2. Adjusted model (B) with 2 residual covariance paths: (LBOA1D with LBOC3D; LHLC2A with LHLC1D) and removed items (LJOP1D, LJOP2D, LJOC2A, LJOM3A, LAXP2D, LAXP2D, LAXC3A, LHLP1B, LHLP2D)

\begin{tabular}{|c|c|c|c|c|c|}
\hline Time point & $\chi 2, \mathrm{df}$ & CFI / TLI & RMSEA (95\%CI) & $\begin{array}{l}\text { Items R2 below } \\
0.25\end{array}$ & Factor $r$ above 0.80 \\
\hline 2010 & $\begin{array}{l}1886.696 \\
519\end{array}$ & $\begin{array}{l}0.911 / \\
0.903\end{array}$ & $0.066(0.063 ; 0.070$ & & A-H: 0.913 \\
\hline 2011 & $\begin{array}{l}2070.889 \\
519\end{array}$ & $\begin{array}{l}0.916 / \\
0.909\end{array}$ & $0.059(0.057 ; 0.062)$ & & A-H: 0.914 \\
\hline 2012 & $\begin{array}{l}2297.568, \\
519\end{array}$ & $\begin{array}{l}0.916 / \\
0.909\end{array}$ & $0.062(0.059 ; 0.065)$ & & A-H: 0.901 \\
\hline
\end{tabular}

Note. $\mathrm{A}=$ Anxiety $; \mathrm{H}=$ Hopelessness.

Table 3. Adjusted model (B):

Standardized factor loadings, factor correlations, and residual covariance paths for the four data sets

\begin{tabular}{llll}
\hline \hline Time point & 2010 & 2011 & 2012 \\
\hline \hline Factor loadings & & & \\
E by LJOA1B & 0.709 & 0.700 & 0.699 \\
E by LJOM1D & 0.691 & 0.624 & 0.646 \\
E by LJOA2D & 0.823 & 0.820 & 0.822 \\
E by LJOC1D & 0.852 & 0.857 & 0.839 \\
E by LJOA3D & 0.651 & 0.656 & 0.654 \\
E by LJOM2A & 0.619 & 0.639 & 0.592 \\
A by LAXM1B & 0.767 & 0.710 & 0.722 \\
A by LAXP1B & 0.848 & 0.798 & 0.770 \\
A by LAXA1B & 0.777 & 0.757 & 0.741 \\
A by LAXC1D & 0.730 & 0.745 & 0.734 \\
A by LAXM2D & 0.674 & 0.630 & 0.633 \\
A by LAXA2D & 0.804 & 0.800 & 0.780 \\
A by LAXC2D & 0.805 & 0.781 & 0.822 \\
A by LAXA3A & 0.669 & 0.683 & 0.641 \\
B by LBOM1B & 0.738 & 0.675 & 0.707 \\
B by LBOM2B & 0.733 & 0.624 & 0.652 \\
B by LBOP1D & 0.752 & 0.752 & 0.780 \\
\hline
\end{tabular}




\begin{tabular}{|c|c|c|c|}
\hline B by LBOP2D & 0.774 & 0.764 & 0.791 \\
\hline B by LBOC3D & 0.621 & 0.618 & 0.597 \\
\hline B by LBOA1D & 0.799 & 0.801 & 0.810 \\
\hline B by LBOC1D & 0.741 & 0.695 & 0.748 \\
\hline B by LBOP3D & 0.864 & 0.823 & 0.870 \\
\hline B by LBOA2D & 0.871 & 0.820 & 0.842 \\
\hline B by LBOA3D & 0.693 & 0.672 & 0.670 \\
\hline B by LBOC2D & 0.830 & 0.778 & 0.837 \\
\hline H by LHLA1B & 0.867 & 0.839 & 0.873 \\
\hline H by LHLM1D & 0.802 & 0.753 & 0.770 \\
\hline H by LHLM2D & 0.792 & 0.751 & 0.782 \\
\hline H by LHLC1D & 0.781 & 0.749 & 0.760 \\
\hline H by LHLA2D & 0.877 & 0.851 & 0.873 \\
\hline H by LHLC $2 A$ & 0.783 & 0.778 & 0.791 \\
\hline H by LHLC3A & 0.788 & 0.742 & 0.791 \\
\hline H by LHLA3A & 0.763 & 0.679 & 0.771 \\
\hline H by LHLC4A & 0.782 & 0.752 & 0.774 \\
\hline \multicolumn{4}{|l|}{ Factor correlations } \\
\hline A with E & -0.565 & -0.479 & -0.533 \\
\hline B with E & -0.555 & -0.461 & -0.548 \\
\hline B with A & 0.448 & 0.400 & 0.357 \\
\hline $\mathrm{H}$ with $\mathrm{E}$ & -0.590 & -0.540 & -0.618 \\
\hline $\mathrm{H}$ with $\mathrm{A}$ & $0.913 \#$ & $0.914 \#$ & $0.901 \#$ \\
\hline H with $B$ & 0.543 & 0.460 & 0.494 \\
\hline \multicolumn{4}{|l|}{ Residual covariance paths } \\
\hline LBOA1D with LBOC3D & -0.240 & -0.206 & -0.125 \\
\hline LHLC2A with LHLC1D & 0.275 & 0.285 & 0.240 \\
\hline
\end{tabular}

Note $. \mathrm{E}=$ Enjoyment; $\mathrm{A}=$ Anxiety $; \mathrm{B}=$ Boredom $; \mathrm{H}=$ Hopelessness. All values statistically significant at the $\alpha$ $=0.005$ level, the largest $\mathrm{p}$-value is approximately 0.001 . The '\#' factor correlations above 0.80 . 
As can be seen from Table 3, the same items load on the same factors across all cohorts. Imposing equality constraints for factor loadings across cohorts would lead to loss of fit and imply a bad fitting model rather than a more parsimonious model with a fair fit. Again, we identified high correlations (factor $r$ above .90) between the Anxiety and Hopelessness factors. Still, the correlations between the other factors were in the range of .40 and .60 . Overall, a four-factor structure according to the theoretically distinct concepts as proposed by Pekrun et al. (2002) is consistent within the course investigated in our study.

\section{Descriptives}

Before presenting the outcomes of testing the hypotheses, mean levels for the four LREs for all participants and then decomposed per gender, previous education and prior level of math are summarized in Table 4 and Table 5.

Table 4. Means (M), standard deviations (SD) and Cronbach's alpha of the adjusted four learning emotions scales, for all participants

\begin{tabular}{lllllllllll}
\hline & $\begin{array}{c}\text { Time } \\
\text { point }\end{array}$ & & & & & & & & \\
& \multicolumn{1}{c}{2010} & & & 2011 & & & 2012 & & \\
& $\mathrm{M}$ & $\mathrm{SD}$ & $\alpha$ & $\mathrm{M}$ & $\mathrm{SD}$ & $\alpha$ & $\mathrm{M}$ & $\mathrm{SD}$ & $\alpha$ \\
\hline Enjoyment & 3.95 & 1.12 & 0.867 & 3.87 & 1.10 & 0.862 & 3.99 & 1.07 & 0.855 \\
Anxiety & 3.71 & 1.27 & 0.915 & 3.60 & 1.21 & 0.905 & 3.75 & 1.23 & 0.902 \\
Boredom & 2.88 & 1.15 & 0.938 & 2.84 & 1.08 & 0.924 & 2.86 & 1.13 & 0.934 \\
Hopelessness & 2.99 & 1.28 & 0.944 & 2.92 & 1.18 & 0.929 & 3.01 & 1.28 & 0.941 \\
\hline
\end{tabular}

Note. $N=600$ for $2010, N=847$ for 2011 and $N=890$ for 2012 .

Table 5. Means (M), standard errors (SE) of the four learning emotions decomposed for Gender, previous education and Math level

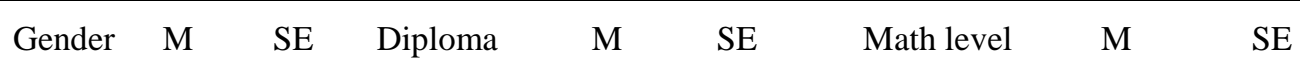

\begin{tabular}{lllllllllll}
\hline Enjoyment & Female & 3.92 & 0.03 & International & 4.11 & 0.02 & Math major & 4.16 & 0.04 \\
& Male & 3.90 & 0.03 & Dutch & 3.70 & 0.04 & Math minor & 3.65 & 0.03 \\
Anxiety & Female & 3.69 & 0.04 & International & 3.59 & 0.03 & Math major & 3.23 & 0.04 & \\
& Male & 3.47 & 0.03 & Dutch & 3.56 & 0.05 & Math minor & 3.92 & 0.03 \\
\multirow{2}{*}{ Boredom } & Female & 2.87 & 0.03 & International & 2.71 & 0.02 & Math major & 2.85 & 0.04 \\
\hline
\end{tabular}




\begin{tabular}{llllllllll}
\hline & Male & 3.02 & 0.03 & Dutch & 3.18 & 0.04 & Math minor & 3.04 & 0.03 \\
Hopelessness & Female & 3.03 & 0.04 & International & 2.81 & 0.03 & Math major & 2.57 & 0.04 \\
& Male & 2.83 & 0.03 & Dutch & 3.05 & 0.05 & Math minor & 3.29 & 0.03 \\
\hline
\end{tabular}

As can be seen from Table 5, females are, on average, more anxious and more hopeless while males are more bored. Furthermore, international students enjoy the course more than Dutch students who are, on average, more bored and hopeless. Finally, having a MathMajor level makes students enjoy more the course while feeling less hopelessness, less anxiety and less boredom towards the course than fellow students with a MathMinor prior level.

\section{Hypothesis 1}

In H1 we assumed differences in the four LREs between the students who attended as compared to those who did not show up to the exam. Since the design was rather unbalanced with respect to the same size of the groups, we tested the equality of covariance matrices using Box's $M$ test. Results of Box's $M$ test (14.999) were not significant $(p=0.142)$ which indicated that the assumption of equality of covariance matrices was met. Results of MANOVA reveal overall significant effects (Pillai's Trace $=0.006, \mathrm{~F}=3.571, p=0.007$ ) for all of the four LREs (detailed values are displayed in Table 6). Although of very small magnitude (partial eta-squared $=0.006$ ), these effects are in the expected direction: on average, students who were absent at the exam enjoyed less, were more anxious, more bored and more hopeless learning for the course, than the students who attended the final exam.

Table 6. Means (M), standard errors (SE) of the adjusted four learning emotions scales decomposed for exam participation, and F-values for the MANOVA Analysis

\begin{tabular}{llllll}
\hline & Exam Participation & $\mathrm{M}$ & $\mathrm{SE}$ & $\mathrm{F}$ & Eta-squared \\
\hline \multirow{2}{*}{ Enjoyment } & Present & 3.96 & 0.02 & $4.566^{*}$ & 0.002 \\
& Absent & 3.69 & 0.12 & & \\
\multirow{3}{*}{ Anxiety } & Present & 3.67 & 0.03 & $8.666^{* *}$ & 0.004 \\
& Absent & 4.09 & 0.14 & & \\
\multirow{3}{*}{ Boredom } & Present & 2.85 & 0.02 & $11.208^{* *}$ & 0.005 \\
& Absent & 3.28 & 0.13 & & \\
\hline
\end{tabular}




\begin{tabular}{llllll}
\hline Hopelessness & Present & 2.96 & 0.03 & $8.222^{* * *}$ & 0.004 \\
& Absent & 3.37 & 0.14 & & \\
\hline
\end{tabular}

Note. $N=2256$ present, $N=81$ absent $; *<.05 ; * * p<.01$.

\section{Hypothesis 2}

In H2 we assumed that the four LREs are able to predict students' performance in the course. Furthermore, we expected the positive LRE of enjoyment to have a positive influence on students' performance and the negative emotions to have a negative influence on performance. Given the high correlations between Hopelessness and Anxiety, before interpreting the regression results, the assumption of non-multicollinearity was also assessed. VIF and Tolerance statistic indicate that the results of the regression were not biased: Tolerance statistic values are above 0.20 (Menard, 1995) for all the factors, while VIF are far below 10 (Myers, 1990). We first investigated the hypothesized relations in the 2010 sample. For a cross validation, we then looked at the same relations in the following two academic years (2011, 2012). The results of the multiple linear regression analyses as well as of the simple linear regression are presented for each academic year in Table 7, Table 8 and Table 9 respectively. Concerning their predictive value, the four LREs together with a prior level of Math are able to explain $18 \%$ variance in grade in the 2010 cohort. The results are pretty similar for 2011 and 2012 respectively: $19 \%$ and 14\% variance is explained in grade, with a dominant contribution of Hopelessness and MathMajor. Furthermore, not in line with the expected relations, Anxiety and Boredom are not significant predictors of grade in 2010; these results replicate for 2011 or 2012. Enjoyment is statistically significant in 2010 only. Hopelessness and MathMajor, on the other hand, are statistically significant in 2010 and, repeatedly in 2011 and 2012; this indicates them as consistent predictors of grade across different cohorts. Subsequent linear regression also reveals that Hopelessness and MathMajor are the only consistent predictors of Grade: higher Hopelessness predicts a lower grade while having been previously educated in Math (having a MathMajor background) leads to a higher grade. Regarding the size and direction of the expected relations, Hopelessness indicates a medium to somewhat strong negative (Lipsey \& Wilson, 2001) effect on grade. This effect is comparable for all data sets: standardized regression coefficients $(\beta$ 's) in the full model are in 2010, 2011 and 2012 respectively: $-0.277,--0.346,-0.370 ; \beta$ 's in the only (Hopelessness and MathMajor) model are in chronological order: $-0.344,-0.391,-0.329$. Enjoyment $(\beta=0.096)$ has only a positive small effect on grade, and that is exclusively true for the 2010 cohort. 
Table 7. Summary of the regression analyses for variables predicting Grade in $\mathbf{2 0 1 0}$

\begin{tabular}{|c|c|c|c|c|}
\hline & $B(S E)$ & $\beta$ & Collinearity & Statitics \\
\hline \multicolumn{5}{|c|}{ Demographics model } \\
\hline Gender & $-0.204(0.182)$ & -0.046 & & \\
\hline Prior education & $-0.221(0.203)$ & -0.045 & & \\
\hline Math Major & $1.311(0.190)$ & $0.288 * * *$ & & \\
\hline$R^{2}$ & 0.082 & & & \\
\hline Full model & & & Tolerance & VIF \\
\hline Enjoyment & $0.186(0.094)$ & $0.096^{*}$ & 0.633 & 1.580 \\
\hline Anxiety & $-0.052(0.124)$ & -0.031 & 0.274 & 3.655 \\
\hline Boredom & $0.068(0.090)$ & 0.036 & 0.638 & 1.568 \\
\hline Hopelessness & $-0.434(0.131)$ & $-0.258 * *$ & 0.244 & 4.097 \\
\hline Math Major & $0.877(0.182)$ & $0.194 * * *$ & 0.916 & 1.092 \\
\hline$R^{2}$ & 0.179 & & & \\
\hline \multicolumn{5}{|l|}{ Only model } \\
\hline Hopelessness & $-0.526(0.067)$ & $-.313 * * *$ & & \\
\hline Math Major & $0.919(0.180)$ & $0.203 * * *$ & & \\
\hline$R^{2}$ & 0.172 & & & \\
\hline
\end{tabular}

Note. All values statistically significant at the $\alpha=0.005$ level, the largest p-value is approximately 0.001 .

Table 8. Summary of the regression analyses for variables predicting Grade in 2011

\begin{tabular}{lllll}
\hline & $B(S E)$ & $\beta$ & Collinearity & Statitics \\
\hline $\begin{array}{l}\text { Demographics } \\
\text { model }\end{array}$ & & & \\
Gender & $-0.056(0.147)$ & -0.013 & & \\
Diploma & $0.358(0.175)$ & 0.069 & & \\
Math Major & $1.266(0.151)$ & $0.283^{* * *}$ & & \\
$R^{2}$ & 0.090 & & & \\
Full model & & Tolerance & VIF \\
Enjoyment & $-0.023(0.073)$ & -0.012 & 0.696 & 1.437 \\
Anxiety & $-0.043(0.101)$ & -0.025 & 0.299 & 3.350 \\
Boredom & $0.024(0.073)$ & 0.012 & 0.731 & 1.367 \\
Hopelessness & $-0.579(0.108)$ & $-.325^{* * *}$ & 0.273 & 3.661 \\
Math Major & $0.862(0.151)$ & $0.193^{* * *}$ & 0.885 & 1.129 \\
$R^{2}$ & 0.188 & & & \\
Only model & & & & \\
Hopelessness & $-0.595(0.059)$ & $-.335^{* * *}$ & & \\
Math Major & $0.868(0.148)$ & $0.194^{* * *}$ & & \\
$R^{2}$ & 0.187 & & & \\
\hline
\end{tabular}

Note. All values statistically significant at the $\alpha=0.005$ level, the largest p-value is approximately 0.001 . 
Table 9. Summary of the regression analyses for variables predicting Grade in 2012

\begin{tabular}{lllll}
\hline & $B(S E)$ & $\beta$ & Collinearity & Statitics \\
\hline Demographics model & & & & \\
Gender & $-0.203(0.157)$ & -0.044 & & \\
Diploma & $-0.203(0.157)$ & 0.049 & & \\
Math Major & $1.188(0.162)$ & $0.246^{* * * *}$ & & \\
$\mathrm{R}^{2}$ & 0.066 & & & \\
Full model & & & Tolerance & VIF \\
Enjoyment & $-0.169(0.090)$ & -0.079 & 0.581 & 1.721 \\
Anxiety & $0.060(0.104)$ & 0.033 & 0.326 & 3.066 \\
Boredom & $-0.056(0.081)$ & -0.027 & 0.661 & 1.513 \\
Hopelessness & $-0.610(0.111)$ & $-0.340^{* * *}$ & 0.270 & 3.704 \\
Math Major & $0.908(0.162)$ & $0.188^{* * * *}$ & 0.920 & 1.087 \\
$\mathrm{R}^{2}$ & 0.141 & & & \\
Only model & & & & \\
Hopelessness & $-0.508(0.060)$ & $-0.283^{* * * *}$ & & \\
Math Major & $0.869(0.160)$ & $0.180^{* * * *}$ & & \\
$\mathrm{R}^{2}$ & 0.137 & & & \\
\hline
\end{tabular}

Note. All values statistically significant at the $\alpha=0.005$ level, the largest p-value is approximately 0.001 .

\section{Discussion}

This investigation extends the scope of previous research in primary and secondary education (Dettmers et al., 2011; Goetz et al., 2012; Trautwein et al., 2009) to look at the role of learning-related emotions in predicting achievement outcomes in the first year of university. To our best knowledge, only few studies in first year samples (Putwain, Larkin et al., 2013) tried to prove similar relations (Tempelaar et al., 2012; Putwain, Sander et al., 2013). Most notably, we found that learning hopelessness, together with a previous mathematics background, are able to predict substantially academic achievement. Furthermore, this relation was confirmed over different cohorts in three consecutive academic years. The fact that having a previous mathematics background enables students to obtain a higher grade is 
not surprising: recent studies have already confirmed this finding (Alexander, 2005; Tempelaar et al., 2012). However, showing a negative emotion, Hopelessness, as the strongest predictor of academic achievement is an important outcome that deserves further elaboration. On one hand, it aligns with the studies of Dettmers et al. (2011) and Trautwein et al. (2009) which showed that indeed negative emotions during homework predict negative achievement. On the other hand, it differs from these studies in two regards: these authors used either single items (Dettmers et al., 2011) or a composite measure of negative emotions including anger, anxiety and boredom (Trautwein et al., 2009). We show that discrete learning hopelessness measured with multiple items - are the strongest factor for achievement in mathematics and statistics. One aspect to stress is that even though high correlations were found between the hopelessness and anxiety factors (at all-time points), the chance of a suppression effect was rejected by additional analyses which showed no real concern of multicollinearity in the data. Consequently, as not all factors had the same influence in predicting achievement - and since learning hopelessness was shown to have the strongest contribution - future efforts should assess particularly this factor in mathematics and statistics courses.

Next, we looked at differences in LREs between students who attended, as compared to those who were absent for the first round of final examination. In line with earlier studies (Ruthig et al., 2008), we found that students who were absent for the exam experienced less enjoyment, more anxiety, more boredom and more hopelessness than the students who attended the final exam. What is particularly relevant is that these differences were already visible in week four, half-way through the course. This knowledge offers the opportunity to intervene early in an educational setting, using these emotions as potential indicators for early withdrawal at the course level.

Finally, some methodological concerns should be outlined. First, while confirming the theoretical model described in the original AEQ posed some fit problems, a better fit on the separate datasets was achieved after removing a set of items. Most of these items were reflecting a physiological component within an emotion. We consider this modification reasonable for the context of learning outside the classroom in a mathematics and statistics course: certain emotional components, such as the cognitive, affective or motivational, could play a more important role in the emotional experience of learning than the physiological one. More explicitly, "getting physically excited when the QM course is going well" or "when the QM course is going well, it gives me a rush" might not be the most relevant items - in terms of 
describing the particular emotional experience of learning in this course. From a methodological point of view, it further indicates that the choice of items made to accurately capture students' emotional experiences should depend on the particular context in which a student is placed within a certain course (such as learning while doing homework as compared to taking an exam). Second, concerning the factorial invariance of the instrument, we found that a fourfactor structure according to the theoretically distinct concepts as proposed by Pekrun et al. (2002) was stable within the subject of Mathematics and Statistics. Since we focused on discrete LREs, we observe a consistent finding across all time points: the co-occurrence (factor $r$ above .90) of the Anxiety and Hopelessness factors. In our sample, this could be explained by conceptual differences in the emotional components (physiological, affective, cognitive and emotional) - which were not taken into account in the original item construction (Pekrun et al., 2004). To date, previous studies testing the divergent validity of these two emotions argue that while anxiety is characterized by motivation to avoid failure, hopelessness shows low motivation and resignation (Pekrun et al., 2004). At last, such a finding can be explained by the fact that both concepts fall under the same category of low control emotions (Scherer, 2005).

\section{Limitations and further research}

Our study used an ecological design to make a good case for the value of LREs as predictors of academic achievement in a mathematics and statistics course in the first year of university study. The design included a large sample and an instrument with confirmed validity and reliability. However, as with any new design, some limitations exist.

First, for the prediction of achievement outcomes, we only focused on average effects in our sample. Such an approach overlooks the amount of intra-individual variability and therefore does not take into account the individual differences in academic performance. Future studies that aim to go beyond the group level of predicting achievement should employ a design able to capture such information.

Second, we measured LREs midway through the course, assuming that they would remain relatively stable. Although students need a minimum period to get an impression of the new educational environment, we cannot be sure whether assessing their emotional experiences earlier in the course could have also proven to be useful for a reliable prediction of 
outcomes. Future research could make use of an earlier assessment and test the individual stability of students' emotional experiences; this could be used to longitudinally predict if students will attend the final exam and, for those who will, explain their performance in the course.

Third, we referred to only one course to draw our conclusions concerning the relation between LREs and achievement. To further show that this is indeed specific for particular academic subjects, such as Mathematics and Statistics, the same relation should be replicated over different academic subjects and across more student samples.

\section{Recommendations for educational practice}

The results of this study become particularly relevant when considering how they can be translated into everyday practice. Accordingly, this could help both students as well as educators in participating to- and co-creating what has been previously referred to as "emotionally sound" educational environments (Astleitner, 2005). One example is a recent study by Paoloni (2014), which suggests implications for practice at various levels involving: studnets'cognitive or motivational resources and self-regulation and feedback processes. In order to address such educational goals, we suggest two main practical recommendations which are based on our findings.

The first finding refers to the role of hopelessness in how students perform academically. From this perspective, educational interventions could focus particularly at decreasing its intensity - as early as possible in a course - as hopelessness is an outcome-focused, prospective emotion which needs time to develop over a course. There is consensus that emotions can be influenced through their antecedents (Pekrun et al., 2006), so hopelessness could be indirectly targeted at this level. For instance, Tempelaar et al. (2012) study focused on epistemological views about effort in mathematics and statistics course - a component of the implicit theories of intelligence model (Dweck, 1999) - as distal antecedents of achievement emotions (Tempelaar et al., 2012). They concluded that negative effort views - the belief students hold towards exerting effort as something which signals lacks of intelligence, therefore negative - had a substantial impact on learning hopelessness (as expressed in a $\beta$ estimate of .86). Effort beliefs however, are in Dweck's (1990) view still malleable and can be intervened 
upon. Future interventions could address such an antecedent, in an effort to prevent the development of hopelessness over a mathematics and statistics course.

The second finding refers to the role of previous knowledge, having a mathematics major or minor background, in how students perform in the course. In this respect, effective interventions are known in helping students' performance by improving their prior knowledge (Rienties et al., 2008). Rienties et al. (2008) designed a series of online remedial programs especially for prospective first year students at university. One of these interventions was conducted in a mathematics course and showed that it is possible to improve deficient prior knowledge of students before entering the university. The effects were shown on both short term in student performance in the course, and on long term on study success in the first year at university. Educational practice could adopt such programs given their proved effectiveness in improving student success as well as for their cost-effectiveness.

\section{Conclusion}

Our study draws upon previous research using the CVTAE to show the value of learning-related emotions as predictors of achievement outcomes in a mathematics and statistics course. We found the four LREs investigated here, as well as a mathematics background, as useful predictors for the exam scores. In particular, negative achievement was mainly predicted by the negative emotion hopelessness. Knowing this course took place in a period of transition - the first year of university study, together with the fact that absent students experienced more unpleasant emotions than students who participated in the exam, points to an early identification of these student characteristics as potential indicators for early withdrawal at the course level. Beyond the prevention of student withdrawal, our study suggests theoretically- and empirically-proven possibilities for improving success in the first year at university study. 


\section{References}

Alexander, P. A. (2005). Psychology in learning and instruction. Prentice Hall.

Arias Ortiz, E., \& Dehon, C. (2013). Roads to success in the Belgian French community's higher education system: Predictors of dropout and degree completion at the Université Libre de Bruxelles. Research in Higher Education, 54(6), 693-723. doi:10.1007/s11162-013-9290-y

Astleitner, H. (2000). Designing emotionally sound instruction: The FEASP-approach. Instructional Science, 28(3), 169-198. doi:10.1023/A:1003893915778.

Baker, R. W., \& Siryk, B. (1999). SACQ Student Adaptation to College Questionnaire (2nd edition ed). Los Angeles: Western Psychological Services.

Barrows, H. \& Tamblyn, R. (1980). Problem based learning: An approach to medical educa tion. New York, Springer.

Beard, C., Clegg, S., \& Smith, K. (2007). Acknowledging the affective in higher education. British Educational Research Journal, 33(2), 235-252 doi:10.1080/01411920701208415

Byrne, B. M. (2011). Structural equation modelling with Mplus. Routledge: New York.

Credé, M., \& Niehorster, S. (2011). Adjustment to college as measured by the Student Adap tation to College Questionnaire: A quantitative review of its structure and relationships with correlates and consequences. Educational Psychology Review, 24(1), 133165. doi:10.1007/s10648-011-9184-5

Daniels, L. M., Perry, R. P., Stupnisky, R. H., Stewart, T. L., Newall, N. E. G., \& Clifton, R. A. (2014). The longitudinal effects of achievement goals and perceived control on university student achievement. European Journal of Psychology of Education, 29(2), 175-194. doi:10.1007/s10212-013-0193-2

Dettmers, S., Trautwein, U., Lüdtke, O., Goetz, T., Frenzel, A. C., \& Pekrun, R. (2011). Stu dents' emotions during homework in mathematics: Testing a theoretical model of an 
tecedents and achievement outcomes. Students' Emotions and Academic Engagement, 36(1), 25-35. doi:10.1016/j.cedpsych.2010.10.001

Dweck, C. S. (1999). Self-theories: Their role in motivation, personality, and development. Philadelphia: Psychology Press

Elliot, A. J., \& Pekrun, R. (2007). Emotion in the hierarchical model of approach-avoidance achievement motivation. In P. A. Schutz \& R. Pekrun (Eds.), Emotion in education. (pp. 57-73). San Diego, CA US: Elsevier Academic Press.

Ergene, T. (2003). Effective interventions on test anxiety reduction: A meta-analysis. School Psychology International, 24(3), 313-328. doi:10.1177/01430343030243004

Fredrickson, B. L. (2001). The role of positive emotions in positive psychology: The broaden-and-build theory of positive emotions. American Psychologist, 56, 218-226. doi: 10.1037/0003-066X.56.3.218.

Gal, I., \& Ginsburg, L. (1994). The role of beliefs and attitudes in learning statistics: Towards an assessment framework. Journal of Statistics Education, V2N2: Gal. (n.d.). Retrieved from http://www.amstat.org/publications/jse/v2n2/gal.htmlGarfield,

J., \& Ben-Zvi, D. (2007). How students learn statistics revisited: A current re view of research on teaching and learning statistics. International Statistical Re view, 75(3), 372-396. doi:10.1111/j.1751-5823.2007.00029.x

Goetz, T., Lüdtke, O., Nett, U. E., Keller, M. M., \& Lipnevich, A. A. (2013). Characteristics of teaching and students' emotions in the classroom: Investigating differences across domains. Contemporary Educational Psychology, 38(4), 383-394. doi:10.1016/j.cedpsych.2013.08.001

Goetz, T., Nett, U. E., Martiny, S. E., Hall, N. C., Pekrun, R., Dettmers, S., \& Trautwein, U. (2012). Students' emotions during homework: Structures, self-concept antecedents, and achievement outcomes. Noncognitive Skills in Education: Emerging Research and Applications in a Variety of International Contexts, 22(2), 225-234. doi:10.1016/j.lindif.2011.04.006

Goetz, T., Pekrun, R., Hall, N., \& Haag, L. (2006). Academic emotions from a socialcognitive perspective: Antecedents and domain specificity of students' affect in the 
context of Latin instruction. British Journal of Educational Psychology, 76(2), 289308. doi:10.1348/000709905X42860

Hyde, J. S., Fennema, E., Ryan, M., Frost, L. A., \& Hopp, C. (1990). Gender comparisons of mathematics attitudes and affect. Psychology of Women Quarterly, 14(3), 299-324. doi:10.1111/j.1471-6402.1990.tb00022.x

Hu, L., \& Bentler, P. M. (1999). Cutoff criteria for fit indexes in covariance structure analysis: Conventional criteria versus new alternatives. Structural Equation Modeling: A Multidisciplinary Journal, 6(1), 1-55. doi:10.1080/10705519909540118

IBM Corp. Released 2013. IBM SPSS Statistics for Windows, Version 22.0. Armonk, NY: IBM Corp.

Lazarus, R. S., \& Folkman, S. (1984). Stress, appraisal, and coping. New York: Springer.

Leone, C., \& Richards, H. (1989). Classwork and homework in early adolescence: The ecology of achievement. Journal of Youth and Adolescence, 18(6), 531-548. doi:10.1007/BF02139072

Lindberg, S. M., Hyde, J. S., Petersen, J. L., \& Linn, M. C. (2010). New trends in gender and mathematics performance: A meta-analysis. Psychological Bulletin, 136(6), 1123 1135. doi:10.1037/a0021276

Linnenbrink, E. A. (2006). Emotion research in education: Theoretical and methodological perspectives on the integration of affect, motivation, and cognition. Educational Psychology Review, 18(4), 307-314. doi:10.1007/s10648-006-9028-x

Linnenbrink-Garcia, L., \& Pekrun, R. (2011). Students' emotions and academic engagement: Introduction to the special issue. Contemporary Educational Psychology, 36(1), 1-3. doi:10.1016/j.cedpsych.2010.11.004

Lipsey, M. W., \& Wilson, D. B. (2001). Practical meta analysis. Applied social research methods series, Vol. 49.

Menard, S. (1995). Applied logistic regression analysis: Sage university series on quantitative applications in the social sciences. Thousand Oaks, CA. 
Myers, R. H. (1990). Classical and modern regression with applications (Vol. 2). Belmont, CA: Duxbury Press.

Muthén, L. K., \& Muthén, B. O. (1998-2011). Mplus User's Guide. Sixth Edition. Los Angeles, CA: Muthén \& Muthén.

Noftle, E. E., \& Robins, R. W. (2007). Personality predictors of academic outcomes: Big five correlates of GPA and SAT scores. Journal of Personality and Social Psychology, 93(1), 116-130. doi:10.1037/0022-3514.93.1.116

Paoloni, P. V. R. (2014). Emotions in Academic Contexts. Theoretical perspectives and implications for educational practice in college. Electronic Journal of Research in Educational Psychology, 12(3),567-596.ISSN: 1696-2095.2014, no. 34-567http://dx.doi.org/10.14204/ejrep.34.14082

Pascarella, E. T., \& Terenzini, R T. (1991). How college affects students: findings and insights from twenty years of research. San Francisco: Jossey-Bass.

Pascarella,E., \& Terenzini,P.(2005). How college affects students (Vol. 2): A third decade of research. SanFrancisco:Jossey-Bass.

Pekrun, R. (1992). Expectancy-value theory of anxiety: Overview and implications. In D. G. Forgays, T. Sosnowski, \& K. Wrzesniewski (Eds.), Anxiety: Recent developments in cognitive, psychophysiological, and health research. (pp. 23-41). Washington, DC US: Hemisphere Publishing Corp.

Pekrun, R. (2000). A social cognitive, control-value theory of achievement emotions. In J. Heckhausen (Ed.), Motivational psychology of human development. Oxford, England: Elsevier Science.

Pekrun, R. (2006). The control-value theory of achievement emotions: Assumptions, corollaries, and implications for educational research and practice. Educational Psychology Review, 18(4), 315-341. doi:10.1007/s10648-006-9029-9

Pekrun, R., Goetz, T., Frenzel, A. C., Barchfeld, P., \& Perry, R. P. (2011). Measuring emo tions in students' learning and performance: The Achievement Emotions Question 
naire (AEQ). Contemporary Educational Psychology, 36(1), 36-48. doi:10.1016/j.cedpsych.2010.10.002

Pekrun, R., Goetz, T., Perry, R. P., Kramer, K., Hochstadt, M., \& Molfenter, S. (2004). Be yond test anxiety: Development and validation of the test emotions questionnaire (TEQ). Anxiety, Stress \& Coping, 17(3), 287-316. doi:10.1080/10615800412331303847

Pekrun, R., Goetz, T., Titz, W., \& Perry, R. P. (2002). Academic emotions in students' selfregulated learning and achievement: A program of qualitative and quantitative re search. Educational Psychologist, 37(2), 91-106. doi:10.1207/S15326985EP3702_4

Pekrun, R., \& Linnenbrink-Garcia, L. (Eds.). (2014). International handbook of emotions in education. New York : Routledge, Taylor \& Francis.

Poropat, A. E. (2009). A meta-analysis of the five-factor model of personality and academic performance. Psychological Bulletin, 135(2), 322-338. doi:10.1037/a0014996

Putwain, D. W., Larkin, D., \& Sander, P. (2013). A reciprocal model of achievement goals and learning related emotions in the first year of undergraduate study. Contemporary Educational Psychology, 38(4), 361-374. doi:10.1016/j.cedpsych.2013.07.003

Putwain, D. W., Sander, P., \& Larkin, D. (2013). Using the $2 \times 2$ framework of achievement goals to predict achievement emotions and academic performance. Learning and Indi vidual Differences, 25(0), 80-84. doi:10.1016/j.lindif.2013.01.006

Richardson, M., Abraham, C., \& Bond, R. (2012). Psychological correlates of university students' academic performance: A systematic review and meta-analysis. Psychological Bulletin, 138(2), 353-387 doi: 10.1037/a0026838

Rienties, B., Tempelaar, D., Dijkstra, J., Rehm, M., \& Gijselaers, W. (2008). Longitudinal study of online remedial education effects. In N. Barsky, M. Clements, J. Ravn, \& K. Smith (Eds.), The Power of Technology for Learning (Vol. 1, pp. 43-59). Springer Netherlands. Retrieved from http://dx.doi.org/10.1007/978-1-4020-8747-9_3 
Robbins, S., Lauver, K., Huy, L., Davies, D., Langley, R., \& Carlstrom, A., (2004). Do psy chological and study skill factors predict college outcomes? A meta-analysis, Psy chological Bulletin, 130 (2), 261-288. doi: 10.1037/0033-2909.130.2.261

Ruthig, J., Perry, R., Hladkyj, S., Hall, N., Pekrun, R., \& Chipperfield, J. (2008). Perceived control and emotions: interactive effects on performance in achievement settings. So cial Psychology of Education, 11(2), 161-180. doi: 10.1007/s11218-007-9040-0

Schutz, P. A., \& Pekrun, R. (2007). Introduction to emotion in education. In P. A. Schutz \& R. Pekrun (Eds.), Emotion in education. (pp. 3-10). San Diego, CA US: Elsevier Academic Press.

Schermelleh-Engel, K., Mossbrugger, H., \& Müller, H. (2003). Evaluating the fit of structural equation models: Tests of significance and descriptive goodness-of-fit measures. Methods of Psychological Research Online, 2, 23-74.

Scherer, K. R. (2005). What are emotions? And how can they be measured? Social Science Information, 44(4), 695-729. doi:10.1177/0539018405058216

Stephanou, G. (2011). Students' classroom emotions: Socio-cognitive antecedents and school performance. Electronic Journal of Research in Educational Psychology, 9(1), 5-48.

Stöber, J., \& Pekrun, R. (2004). Advances in test anxiety research. Anxiety, Stress \& Coping: An International Journal, 17(3), 205-211. doi: 10.1080/1061580412331303225

Tempelaar, D. T., Niculescu, A., Rienties, B., Gijselaers, W. H., \& Giesbers, B. (2012). How achievement emotions impact students' decisions for online learning, and what pre cedes those emotions. The Internet and Higher Education, 15(3), 161-169. doi:10.1016/j.iheduc.2011.10.003

Tinto, V. (1987). Leaving college, Rethinking the causes and cures of student attrition. Chicago: The University of Chicago.

Trautwein, U., Schnyder, I., Niggli, A., Neumann, M., \& Lüdtke, O. (2009). Chameleon ef fects in homework research: The homework-achievement association depends on the measures used and the level of analysis chosen. Contemporary Educational Psycholo gy, 34(1), 77-88. doi:10.1016/j.cedpsych.2008.09.001 
Turner, J. E., \& Schallert, D. L. (2001). Expectancy-value relationships of shame reactions and shame resiliency. Journal of Educational Psychology, 93, 320-329. doi: 10.1037//0022-0663.93.2.320

Verma, S., Sharma, D., \& Larson, R. W. (2002). School stress in India: Effects on time and daily emotions. International Journal of Behavioral Development, 26(6), 500-508. doi:10.1080/01650250143000454

Weiner, B. (1985). An attributional theory of achievement motivation and emotion. Psycho logical Review, 92, 548-573. Wilkerson, L., \& Gijselaers, W. H. (1996). Bringing problem-based learning to higher education: Theory and practice. San Francisco: Jossey-Bass.

Zeidner, M. (1998). Test anxiety: The state of the art. Springer.

Zeidner, M. (2007). Test anxiety in educational contexts: What I have learned so far. In P. A. Schutz \& R. Pekrun (Eds.), Emotion in education (pp. 165-184). San Diego, CA: Academic Press. 